\title{
Modelling of Dewatering Wood Pulp in a Screw Press Using Statistical and Multivariate Analysis
}

\author{
Bouchaib El Idrissi, ${ }^{\mathrm{a}, *}$ Éric Loranger, ${ }^{\mathrm{a}}$ Robert Lanouette, ${ }^{\mathrm{a}}$ Jean Pierre Bousquet, ${ }^{\mathrm{b}}$ and \\ Mark Martinez $^{\mathrm{c}}$
}

\begin{abstract}
Statistical modeling of a screw press was established by using an experimental design based on the screw rotational speed, the pulp feed consistency, the pulp feed suspension freeness, the inlet pressure, and the counter-pressure at the discharge end. The statistical models showed that the screw press outputs for each pulp could be predicted. When including all data in a global model to predict the outputs of the press for any pulp, a global statistical model was found not to be efficient by using just the five fixed parameters. The solution to this problem was to use a multivariate analysis to include more parameters, mainly about the fiber characteristics (crowding factor, fiber length, fiber width, and fines content). By including these fiber properties, the differences between each pulp were more properly analyzed. The multivariate analysis predicted the press outsets very well in a global model by using eight parameters instead of five. The $R^{2}$ values of the multivariate prediction model were all higher than 0.70 and had the goodness of prediction $\left(Q^{2}\right)$ higher than 0.60 .
\end{abstract}

Keywords: Dewatering; Screw press; Wood pulp; Statistical modeling; Multivariate analysis

Contact information: a: I2E3 - Institut d'Innovations en Écomatériaux, Écoproduits et Écoénergies, à base de biomasse, Trois-Rivières, G8Z 4M3, Canada; b: Valmet USA Inc. fibre business line, Duluth,

Minnesota, 30096, USA; c: University of British Columbia, Pulp and Paper Centre, Vancouver, V6T 1Z4, Canada; *Corresponding author: bouchaib.el.idrissi@uqtr.ca

\section{INTRODUCTION}

Screw presses are widely used in mechanical pressing to remove liquid from a variety of suspensions. They are used in food processing industries, especially oil extraction (Bredeson 1983; Indartono et al. 2019), water treatment (Fangueiro et al. 2008), paper industry (Meyer et al. 2018), and more recently, in lignocellulosic biomass pretreatment (Yan et al. 2014). Screw presses are similar to conventional extruders but with a perforated barrel allowing water to be drained and collected as a filtrate. The screw press consists of a helical flight attached to a rotating shaft that transports the material to be dewatered along the press. There are a variety of geometrical properties of the screw press; the shaft can be of a fixed diameter or having a gradually increasing diameter along the press. The screw pitch can be constant or decreasing along the press, the perforated barrel holes size, or the opening percentage.

Attempts to model the screw press dewatering have been based on dividing the press into two zones (Shirato et al. 1985; Egenes and Helle 1994; Eaves et al. 2020). First, the material is dewatered by filtration and moving it along the press to a point where the material starts to become more solid. At this point, there is a pressure build-up, where the dewatering by compression takes over. The models developed by Eaves et al. (2020) are based on two-phase flow formulations by using Darcy's law for the fluid and the effective solid network stress for the solid part. In their paper, they defined the transition point from 
the filtration zone, or as they called it the churning zone, to the consolidation zone or the shunting zone. The transition point position is dictated by the force balances, with the pressure set at the inlet and the counter-pressure maintained at the press exit.

El Idrissi et al. (2019) found that the dewatering in the screw press is controlled by the press operating parameters (rotational speed, inlet pressure, counter-pressure) and the material properties (feed consistency, freeness). It was shown that the main parameter is the rotational speed. The freeness and inlet consistency affect the filtrate properties more. The suspension characteristics, especially the fine content and the fiber length, dictate the range of the operating parameters in a screw press. The fiber length strongly influences the strength of a fiber suspension (Ringnér 1995); thus, it influences the degree to which the formed web can be compressed. Moreover, the crowding factor effect was considered (N) (Mason 1954; Kerekes and Schell 1992). The crowding factor was defined by Kerekes et al. (1992), as the number of fibers in a spherical volume of diameter equal to the length of a fiber. It is used to characterize fibers flocculation in water suspension. This factor affects mobility. In other words, it is an indicator of how fibers can move relatively to one another, as demonstrated by Martinez et al. (2001). Indeed, the crowding factor characterizes the fiber flocculation regimes, as defined by Soszynski (1987). A crowding factor lower than one represents a dilute regime with one chance of collision but, Martinez et al. (2001) modified this statement, and the dilute regime was extended until $\mathrm{N}=60$ at a point they called the gel point. The fibers are continuously in contact when $\mathrm{N}>60$ in a concentrated regime and tend to entangle.

In this article, a statistical model of the screw press using the five parameters previously studied (El Idrissi et al. 2019) was established. JMP software was used based on the experimental designs developed for each pulp. The modeling started by applying a model for each pulp individually, and it proved to be efficient, as good predictive models were found. By including the three pulps data in one model in JMP, only screw press production and filtrate flux could be predicted well. Hence, the need to use another tool was obvious to improve the global predictive model. By applying a multivariate analysis in the EXPLORE software and adding more parameters into the model (fiber length, fiber width, coarseness, crowding factor, fines content), improvements in the prediction performance were expected.

\section{EXPERIMENTAL}

\section{Materials}

This study was conducted on a Thune (Voith) SP23 screw press. The screw press characteristics are detailed in Table 1. The study included three different pulps: softwood kraft pulp, bleached chemi-thermomechanical pulp (BCTMP), and softwood thermomechanical pulp (TMP). The three pulps' properties are summarized in Table 2. It should be noted that according to the crowding factor values of the three pulps, the suspension entering the screw press is above the gel point (Martinez et al. 2001, 2003), which means that there was already good fiber-fiber contact when entering the screw press.

\section{Methods}

The study was based on using experimental designs (Sall et al. 2017) developed in JMP software obtained from the SAS Institute. The first trials were made on kraft pulp, and the experimental design used was a central composite-uniform precision design with 
six central points, giving 32 experiments. Since it appeared that counter-pressure did not affect much of the screw press outputs for kraft pulp, the other designs were organized using the counter-pressure as a blocking factor for BCTMP and TMP. Therefore, the experimental design for BCTMP and TMP was a central composite-orthogonal block design with three central points, giving 27 trials for each pulp. The experimental design levels are summarized in Table 3. The same values for all pulps were not used because when experiments were conducted on BCTMP, the screw press could not handle high rotational speeds and pressure as it did for kraft pulp; thus, the parameters were lowered a bit for BCTMP and TMP. Five operational parameters were chosen based on the operational parameters studied by El Idrissi et al. (2019). The screw rotational speed was varied according to the experimental design performed. The inlet consistency was measured following the procedures in TAPPI T 240 om-93 (1993) method. The freeness (CSF) was determined following the TAPPI T 227 om-99 (1999) method. The feed pressure and the counter-pressure were adjusted manually.

Table 1. Screw Press Dimensions

\begin{tabular}{|c|c|}
\hline Constructor & Thune (Voith) \\
\hline Model & SP23 \\
\hline Engine & Hydraulic, 0-60 rpm \\
\hline Perforated barrel & $230 \mathrm{~mm}$ diameter; holes $1.2 \mathrm{~mm}$ diameter; open area $27.5 \%$ \\
\hline Shaft length & $1448.5 \mathrm{~mm}$ \\
\hline Pressure sensors positions & $586.50 \mathrm{~mm} ; 891.60 \mathrm{~mm} ; 1182.00 \mathrm{~mm} ; 1421.00 \mathrm{~mm}$ \\
\hline
\end{tabular}

Table 2. Initial Pulp Properties

\begin{tabular}{|c|c|c|c|}
\hline Properties & Kraft pulp & BCTMP & TMP \\
\hline Type & Softwood & Hardwood & Softwood \\
\hline Origin & $\begin{array}{c}\text { J. D. Irving, Ltd. } \\
\text { (Saint John, NB, } \\
\text { Canada) }\end{array}$ & $\begin{array}{c}\text { Rayonier Advanced } \\
\text { Materials (Témiscaming, } \\
\text { QC, Canada) }\end{array}$ & $\begin{array}{c}\text { Papier Masson } \\
\text { Ltd. (Gatineau, } \\
\text { QC, Canada) }\end{array}$ \\
\hline Fibres length $\left(\mathrm{Iw}^{*}\right)(\mathrm{mm})$ & 2.03 & 0.81 & 0.91 \\
\hline Fibres width $\left(\mathrm{lw}^{*}\right)(\mu \mathrm{m})$ & 27.0 & 28.6 & 33.9 \\
\hline Fines $\left(\mathrm{Iw}^{*}\right)(\%)$ & 27.5 & 52.3 & 60.7 \\
\hline Coarseness $(\mu \mathrm{g} / \mathrm{m})$ & 181 & 167 & 222 \\
\hline Crowding factor & 285 & 69 & 54 \\
\hline${ }^{*}$ Iw: length weighted & \multicolumn{3}{|l}{} \\
\hline
\end{tabular}

The order of experiments was adjusted to have trials with higher freeness first before adjusting the freeness to a lower value by refining when needed, according to the experimental design developed. The experimental designs allowed the ability to evaluate the performance of the screw press and conduct a statistical predictive model. Six performance indicators were evaluated. The filtrate flux was measured by collecting the drained water in fourteen positions along the screw press. The drained water was stored to measure filtrate consistency and percent fiber loss. The outlet consistency was measured by collecting the dried pulp at the outlet. The screw press production is a calculated value determined by the total solids' concentration and flow to the screw press. The energy consumption was calculated by using the torque values and the rotational speed. Finally,

El Idrissi et al. (2020). "Modelling of pulp dewatering," BioResources 15(3), 5899-5912. 5901 
four pressure sensors along the screw press were installed as discussed in previously published work (El Idrissi et al. 2019), and it was observed that the pressure is affected only near the discharge end; therefore, only the pressure in sensor 4 was predicted.

Table 3. Design Level Values

\begin{tabular}{|c|c|c|c|c|c|c|c|c|c|c|}
\hline Pulp & \multicolumn{3}{|c|}{$\begin{array}{c}\text { Rotational } \\
\text { Speed }\end{array}$} & $\begin{array}{c}\text { Consistency } \\
(\%)\end{array}$ & \multicolumn{2}{c|}{ Freeness $(\mathrm{mL})$} & \multicolumn{2}{c|}{$\begin{array}{c}\text { Feed Pressure } \\
\left(\mathrm{kPa}^{*}\right)\end{array}$} & \multicolumn{2}{c|}{$\begin{array}{c}\text { Counter- } \\
\text { Pressure }(\mathrm{kPa})\end{array}$} \\
\hline Level & -1 & +1 & -1 & +1 & -1 & +1 & -1 & +1 & -1 & +1 \\
\hline Kraft & 22 & 44 & 2 & 4.0 & 176 & 464 & 10 & 30 & 200 & 400 \\
\hline BCTMP & 9 & 44 & 2 & 3.8 & 151 & 328 & 8 & 30 & 200 & 400 \\
\hline TMP & 10 & 34 & 2 & 3.57 & 137 & 276 & 4 & 18 & 200 & 400 \\
\hline
\end{tabular}

The predictive models developed in JMP did not show high goodness of fit for a global model that included the three pulps', so another tool (EXPLORE software, Canmet Energy, Varennes (QC) Canada) was used to include more variables into the multivariate analysis. In addition to the previously cited five parameters, the fiber length, fiber width, fines content, coarseness, and the crowding factor were added to perform a multivariate analysis.

\section{RESULTS AND DISCUSSION}

\section{Individual Model Choice}

The $\mathrm{R}^{2}$ values from each sample were compared to find the best predictive model for each situation. The first model is a linear model based on the five parameters studied. A model with the five parameters plus their interactions could also be used, or the parameters could be included as quadratic terms in a quadratic model. The goodness of fit was compared in terms of $R^{2}$ in Table 4.

Table 4. $R^{2}$ Models Values for Each Pulp

\begin{tabular}{|c|c|c|c|c|c|c|c|}
\hline Pulp & Model & $\begin{array}{c}\text { Outlet } \\
\text { Consistency } \\
(\%)\end{array}$ & $\begin{array}{c}\text { Log (Filtrate } \\
\text { Consistency) } \\
(\%)\end{array}$ & $\begin{array}{c}\text { Filtrate } \\
\text { Flux } \\
(\mathrm{kg} / \mathrm{min})\end{array}$ & $\begin{array}{c}\text { Production } \\
\text { (odmt/d) }\end{array}$ & $\begin{array}{c}\text { Log } \\
\text { (Sensor 4 } \\
\text { Pressure) } \\
(\mathrm{kPa})\end{array}$ & $\begin{array}{c}\text { Log (Energy } \\
\text { Consumption) } \\
(\mathrm{kWh} / \mathrm{kg})\end{array}$ \\
\hline \multirow{3}{*}{ Kraft } & Simple & 0.59 & 0.80 & 0.82 & 0.88 & 0.91 & 0.74 \\
\cline { 2 - 8 } & Interactions & 0.70 & 0.94 & 0.93 & 0.92 & 0.97 & 0.92 \\
\cline { 2 - 8 } & Quadratic & 0.76 & 0.94 & 0.97 & 0.92 & 0.97 & 0.93 \\
\hline \multirow{3}{*}{ BCTMP } & Simple & 0.78 & 0.66 & 0.77 & 0.91 & 0.57 & 0.70 \\
\cline { 2 - 8 } & Interactions & 0.92 & 0.77 & 0.90 & 0.98 & 0.91 & 0.91 \\
\cline { 2 - 8 } & Quadratic & 0.92 & 0.77 & 0.90 & 0.98 & 0.91 & 0.91 \\
\hline \multirow{3}{*}{ TMP } & Simple & 0.72 & 0.38 & 0.88 & 0.90 & 0.66 & 0.61 \\
\cline { 2 - 8 } & Interactions & 0.72 & 0.65 & 0.94 & 0.97 & 0.84 & 0.69 \\
\cline { 2 - 8 } & Quadratic & 0.72 & 0.86 & 0.97 & 0.99 & 0.84 & 0.78 \\
\hline
\end{tabular}


At first glance, a simple model could be a good choice for kraft pulp and BCTMP, but it gave a very low $\mathrm{R}^{2}$ for TMP filtrate consistency. Thus, the simple model was omitted as an option. Then the model with interactions was compared to the quadratic model. Comparing the $\mathrm{R}^{2}$ in Table 4 for these two options, the $\mathrm{R}^{2}$ was not improved by including quadratic terms into the model in order to predict the outputs well. However, by including the quadratic terms, the $\mathrm{R}^{2}$ was slightly improved for TMP filtrate consistency and TMP energy consumption. As a result, the variables affecting the responses were only evaluated using a model with interactions.

The prediction coefficients of the model with interactions are summarized in Table 5. Each coefficient reflects the degree to which a parameter or the parameters interactions affect the related response. They represent the coefficients in the prediction formula, for instance the outlet consistency for kraft pulp is predicted as follows:

\section{Out. Cons. $=33.04+0.4 * C S F+1.32 *$ C.pres. $-2.22 *$ Rot.speed $-1.09 *$ CSF $*$ Rot. speed -$$
0.09 * \text { C.pres. } * \text { Rot. speed }
$$

The freeness and the rotational speed are the two most important parameters, as they either affect a response individually or by interaction with another parameter, this confirms the findings in El Idrissi et al. (2019). The work done by $\mathrm{Xu}$ et al. (2001) on bleached kraft pulp showed that the rotational speed was the most significant and the suspension flow along with the residence time, are more closely related with the rotational speed than to the feed pressure. The same remark was made by Egenes and Helle (1992). Their work on beaten and unbeaten kraft pulp showed that the freeness along with the rotational speed are the most significant factors that define how the pulp is dewatered.

BCTMP had the best prediction for outlet consistency when comparing the models' goodness of fit in Table 4; they seem similar for kraft pulp and TMP. Kraft pulp and TMP are both produced from softwood, so their fibers are not as rigid and stiff as BCTMP, which is from hardwood fibers. This possibly explains the similarity between TMP and BCTMP. Analysis of the data for outlet consistency in Table 5 shows that the freeness is a very important factor for BCTMP but has no effect on TMP and a slight effect on kraft pulp. Considering these facts and keeping in mind that BCTMP is made from hardwood, with more rigid fibers, it explains the difference between this pulp, kraft pulp, and TMP. For the filtrate consistency, a similarity between BCTMP and TMP was observed. Both pulps had almost identical fines content, and by comparing the coefficients in Table 5, both BCTMP and TMP were not affected by the rotational speed, but they were more affected by the feed consistency.

For the filtrate flux, the three pulps showed a good fit. The difference observed was the amount of flow for each pulp. The kraft pulp had a higher filtrate flow rate; it contained longer fibers offering more space for water and fines to slip from the screw press. BCTMP flux was observed to be higher than TMP, even if containing very close fines content and very close operational parameters. This can be explained by the rigidity of BCTMP fibers. The main factors affecting the filtrate flux, as observed in Table 5, are the freeness, the rotational speed, and the feed consistency. The pressure has more effect on BCTMP, as it has more rigid fibers offering more fiber interspace for dewatering under higher pressure, since the pulp pad remains less compact. The other outlet variable is the production rate of the pulps, which is well predicted for the three pulps, with almost no significant difference. It was observed that the screw press production rate was very much affected by the rotational speed and feed consistency (El Idrissi et al. 2019), and this is also observed in Table 5 . 
Table 5. Estimated Coefficients for Models with Interactions of Each Pulp with a Significant Probability at $95 \%$

\begin{tabular}{|c|c|c|c|c|c|c|c|}
\hline Pulp & Terms & \begin{tabular}{|c|} 
Outlet \\
consistency \\
$(\%)$ \\
\end{tabular} & $\begin{array}{c}\text { Filtrate } \\
\text { Consistency } \\
(\%)\end{array}$ & \begin{tabular}{|l} 
Filtrate \\
Flux \\
$(\mathrm{kg} / \mathrm{min})$
\end{tabular} & $\begin{array}{r}\text { Productiol } \\
\text { (odmt/d) }\end{array}$ & $\begin{array}{c}\text { Sensor } 4 \\
\text { Pressure } \\
(\mathrm{kPa})\end{array}$ & $\begin{array}{c}\text { Energy } \\
\text { Consumption } \\
(\mathrm{kWh} / \mathrm{kg})\end{array}$ \\
\hline \multirow[t]{14}{*}{ Kraft } & Intercept & 33.04 & 0.19 & 296.74 & 12.95 & 242.53 & 1.35 \\
\hline & CSF & $0.40^{*}$ & -0.04 & 58.24 & 2.31 & 23.43 & -0.27 \\
\hline & Cons. & - & -0.05 & -33.76 & 3.86 & 33.15 & -0.47 \\
\hline & Pres. & - & 0.06 & 24.82 & 0.76 & 8.08 & - \\
\hline & C.pres. & 1.32 & - & - & - & 33.71 & 0.09 \\
\hline & Rot. speed & -2.22 & 0.05 & 46.33 & 1.96 & -53.98 & 0.09 \\
\hline & CSF $\times$ Cons. & - & 0.02 & -30.84 & -0.51 & -3.21 & 0.23 \\
\hline & CSF $\times$ Pres & - & -0.02 & - & - & - & - \\
\hline & CSF $\times$ C.Pres & - & - & - & - & 8.06 & - \\
\hline & $\begin{array}{l}\text { Cons. } \times \text { Rot. } \\
\text { speed }\end{array}$ & - & - & - & 1.06 & - & -0.09 \\
\hline & Cons. $\times$ Pres. & - & -0.03 & - & - & - & - \\
\hline & CSF $\times$ Rot. speed & -1.09 & - & 12.47 & - & -6.71 & - \\
\hline & Pres. $\times$ Rot. speed & - & 0.02 & - & - & - & - \\
\hline & $\begin{array}{l}\text { C.Pres. } \times \text { Rot. } \\
\text { speed }\end{array}$ & -0.09 & - & - & - & -16.38 & - \\
\hline \multirow[t]{11}{*}{ BCTMP } & Intercept & 28.00 & 0.46 & 252.63 & 8.58 & 252.96 & 1.52 \\
\hline & CSF & 3.82 & -0.17 & - & 1.43 & 78.43 & $0.01^{*}$ \\
\hline & Cons. & 1.49 & -0.43 & -108.77 & 2.02 & 68.13 & -0.33 \\
\hline & Rot. Speed & -11.88 & - & 76.92 & 3.08 & -291.09 & -0.70 \\
\hline & Pres. & - & 0.25 & 87.53 & 1.54 & - & -0.25 \\
\hline & C.Pres. & - & - & - & - & -0.35 & - \\
\hline & CSF $\times$ Cons & -1.53 & - & -- & 1.15 & - & -0.21 \\
\hline & CSF $\times$ Rot. speed & 4.46 & - & - & - & 190.32 & 0.46 \\
\hline & Cons. $\times$ Pres & - & -0.25 & -96.59 & - & - & - \\
\hline & Pres. $\times$ Rot. speed & - & - & - & 0.69 & - & - \\
\hline & $\begin{array}{l}\text { Cons. } \times \text { Rot. } \\
\text { speed }\end{array}$ & - & - & - & - & - & 0.33 \\
\hline \multirow[t]{10}{*}{ TMP } & Intercept & 27.06 & 0.25 & 160.28 & 6.43 & 160.77 & 1.53 \\
\hline & Rot. speed & -7.66 & - & 44.18 & 1.99 & -135.00 & - \\
\hline & CSF & - & -0.09 & 22.51 & 1.13 & $12.26^{*}$ & -0.26 \\
\hline & Cons. & - & -0.10 & -19.34 & 1.76 & 47.66 & -0.40 \\
\hline & Pres. & - & 0.05 & 20.43 & 0.53 & $20.72^{*}$ & - \\
\hline & CSF $\times$ Cons & - & 0.07 & - & - & - & 0.17 \\
\hline & Cons. $\times$ Pres & - & -0.05 & -9.41 & - & 31.43 & - \\
\hline & CSF $\times$ Rot. speed & - & - & 13.14 & 0.51 & 58.45 & - \\
\hline & $\begin{array}{c}\text { Cons. } \times \text { Rot. } \\
\text { speed }\end{array}$ & - & - & - & 0.94 & -18.06 & - \\
\hline & CSF $\times$ Pres & - & - & - & -0.03 & - & - \\
\hline
\end{tabular}

El Idrissi et al. (2020). "Modelling of pulp dewatering," BioResources 15(3), 5899-5912. 5904 
The pressure of interest was that of sensor 4 because the pressure in the other three sensors was very close to the feed pressure. Table 4 shows that the pressure at sensor 4 was very well predicted. The model fit well for BCTMP and kraft pulp, but seemed a bit less efficient for TMP. This is probably due to the fines content, which alters the pressure zones in the compressed pulp in the screw press. From Table 5, it was noted that the rotational speed was the main factor affecting the pressure at sensor 4, which confirms previous findings by El Idrissi et al. (2019). Finally, the energy consumption was very well predicted for kraft pulp and BCTMP, as observed in Table 4. As for TMP, softwood fibers and more fines might have made the motor load fluctuate due to a more sensitive operation, giving a lower prediction. The main factors affecting the energy consumption were the feed consistency and the freeness, as can be observed in Table 5.

\section{General Model}

Individually evaluating each pulp confirmed that the model with interactions predicted the responses very well. For practical purposes, a model that can include the three pulps would be better. Hence, the outputs could be predicted no matter the pulp being dewatered in the screw press. Therefore, a global model was performed by putting all the pulps data in one model using JMP. The global statistical model did not perform as well as expected for some responses. Therefore, the EXPLORE software, which is based on multivariate analysis, had to be used. The multivariate analysis included more complex relationships and additional parameters to increase the goodness of prediction.

\section{General statistical model (JMP)}

A global model was generated by putting the dewatering data of the three pulps in JMP software. As shown in Table 6, three models were established: a simple model including just the five parameters, a model including interactions as well, and a model including quadratic terms. The model with interactions was chosen by comparing the $\mathrm{R}^{2}$ values comparing the three established models based on their $R^{2}$ values. The $R^{2}$ of the model with interactions and the quadratic model was almost equal. The only exception was for the outlet consistency, which was slightly higher in the quadratic model. Thus, the model with interactions is the optimal choice to have a simplified prediction formula with good accuracy. In the global model, only the filtrate flux and the production have a high $\mathrm{R}^{2}$, meaning that they can be predicted very well. For the other responses, it seems that more information was needed to improve the goodness of fit. Table 7 shows the estimation coefficients for the global model with interactions. The rotational speed and freeness are the most important factors, followed by feed consistency.

Table 6. $\mathrm{R}^{2}$ for a Global Model Including the Three Pulps

\begin{tabular}{|c|c|c|c|c|c|c|}
\hline Model & $\begin{array}{c}\text { Outlet } \\
\text { consistency } \\
(\%)\end{array}$ & $\begin{array}{c}\text { Filtrate } \\
\text { Consistency } \\
(\%)\end{array}$ & $\begin{array}{c}\text { Filtrate Flux } \\
(\mathrm{kg} / \mathrm{min})\end{array}$ & $\begin{array}{c}\text { Production } \\
(\text { odmt/d) }\end{array}$ & $\begin{array}{c}\text { Sensor 4 } \\
\text { Pressure } \\
(\mathrm{kPa})\end{array}$ & $\begin{array}{c}\text { Energy } \\
\text { Consumption } \\
(\mathrm{kWh} / \mathrm{kg})\end{array}$ \\
\hline Simple & 0.37 & 0.32 & 0.83 & 0.90 & 0.45 & 0.49 \\
\hline Interactions & 0.40 & 0.38 & 0.86 & 0.94 & 0.54 & 0.54 \\
\hline Quadratic & 0.52 & 0.38 & 0.86 & 0.94 & 0.62 & 0.58 \\
\hline
\end{tabular}


Table 7. Estimated Coefficients for a Global Interaction Model with a Significant Probability at $95 \%$

\begin{tabular}{|c|c|c|c|c|c|c|}
\hline Terms & $\begin{array}{c}\text { Outlet } \\
\text { Consistency } \\
(\%)\end{array}$ & $\begin{array}{c}\text { Filtrate } \\
\text { Consistency } \\
(\%)\end{array}$ & $\begin{array}{c}\text { Filtrate } \\
\text { Flux } \\
(\mathrm{kg} / \mathrm{min})\end{array}$ & $\begin{array}{c}\text { Production } \\
(\text { odmt/d) }\end{array}$ & $\begin{array}{c}\text { Sensor 4 } \\
\text { Pressure } \\
(\mathrm{kPa})\end{array}$ & $\begin{array}{c}\text { Energy } \\
\text { Consumption } \\
(\mathrm{kWh} / \mathrm{kg})\end{array}$ \\
\hline Intercept & 30.83 & 0.23 & 289.76 & 12.38 & 208.04 & 1.35 \\
\hline Freeness & 2.35 & -0.10 & 62.46 & 2.61 & 56.24 & -0.30 \\
\hline Consistency & - & -0.12 & -48.84 & 3.82 & 40.52 & -0.42 \\
\hline Pressure & $1.39^{*}$ & 0.09 & 46.97 & 1.29 & 43.07 & - \\
\hline Rot. speed & -3.65 & - & 48.76 & 2.22 & -65.69 & -0.08 \\
\hline Freeness $\times$ Consist. & - & 0.08 & -17.96 & - & - & 0.18 \\
\hline Freeness $\times$ Pressure & -1.83 & - & - & -0.06 & - & - \\
\hline $\begin{array}{c}\text { Consistency } \times \text { Rot. } \\
\text { Speed }\end{array}$ & - & - & - & 1.11 & -25.90 & -0.10 \\
\hline Consistency $\times$ Pressure & - & -0.06 & -15.50 & 0.53 & - & - \\
\hline Freeness $\times$ Rot. speed & 0.35 & - & 8.84 & - & 47.59 & - \\
\hline * Not significant at 95\%, but term included in interactions \\
\hline
\end{tabular}

\section{General multivariate model (EXPLORE)}

The multivariate analysis in EXPLORE included other parameters than those studied in JMP without having to make a new experimental design. In addition to the five parameters already studied in JMP, five more parameters were added (fiber length, fiber width, fines percentage, crowding factor, and coarseness) to establish a complete Partial Least Square model (PLS). Some outputs did not have a linear relationship. Therefore, they were changed into a $\log$ function. Thus, the filtrate consistency, the pressure of sensor 4 , and the energy consumption were transformed to a log function. The complete model using ten factors was reduced to a model that included only eight factors. The counter-pressure and coarseness were omitted due to their low contribution to the $\mathrm{R}^{2}$ and the goodness of prediction $\mathrm{Q}^{2}$ in the model. Figure 1 shows the variation of the $\mathrm{R}^{2}$ and $\mathrm{Q}^{2}$ of the reduced model according to the number of components included. The reduced model performed very well, and a very good predictive model can be obtained even by stopping at four components.

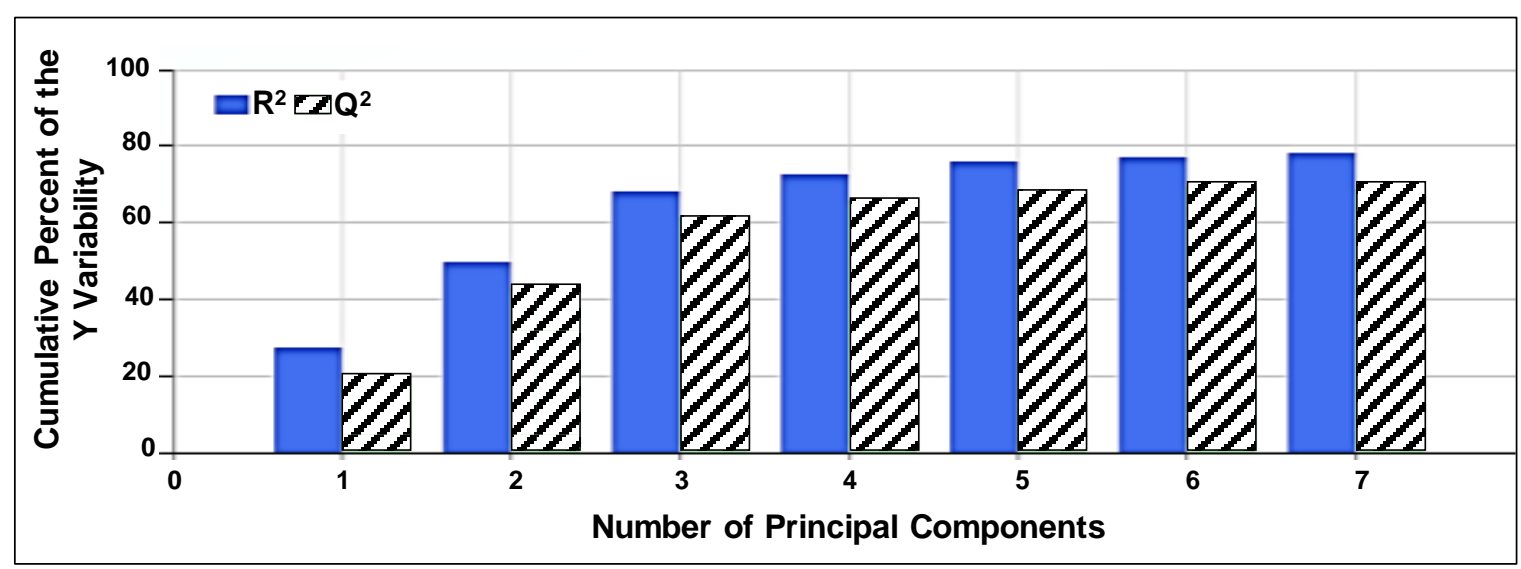

Fig. 1. Percentage of $Y$ variability explained by the PLS model 
In the reduced model established (Fig. 1), the predictive ability was very good, starting from four components. Hence, the loadings and the scores of the model could be analyzed with the basis of these four components (Figs. 2 and 3). The loadings (Fig.2-b), which are the weights of the variables when calculating the scores from the original observations, express the dominating correlation structure of the $\mathrm{X}$ matrix. The model score plot represents the map of the observations.

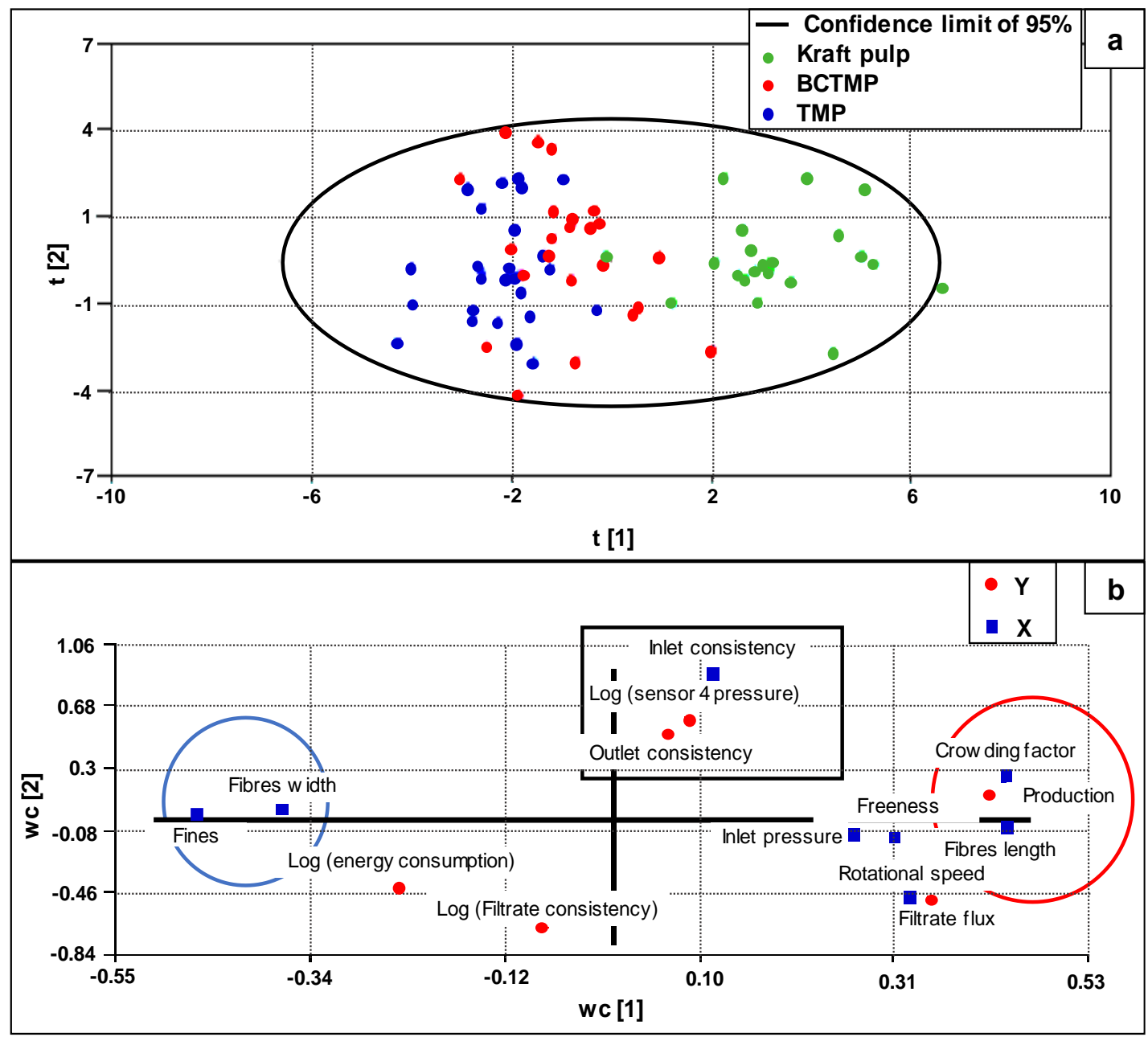

Fig. 2. Scores (a) and loadings (b) of the model for the first and the second latent vectors

The BCTMP and TMP data show some similarities between these two pulps. The scores plot based on the first two components (Fig. 2a) shows that kraft pulp differed from BCTMP and TMP. The data looks divided into three groups. The first latent vector enables the separation of kraft pulp from TMP and BCTMP, mainly based on the fiber characteristics, as shown in the loading plot in Fig. $2 \mathrm{~b}$, such as the fines content and the fiber length. In the loadings plot in Fig. 2b, the variables in the same circle or square provide similar information. The variables situated in the red circle versus variables in the blue circle are negatively correlated, while the variables in the square are not related to the variables in the blue or red circle. The second latent vector seems more related to operating conditions and their effect on consistency and filtrate. For this vector, fiber length and fines are not significant, being close to zero on the vertical axis of the graph. The inlet pressure 
and the rotational speed were inversely related to the fines content, as already observed in a previous study (El Idrissi et al. 2019). It was obviously easier to operate in higher rotational speed and inlet pressure for kraft pulp having around $20 \%$ of fines; however, TMP and BCTMP could not operate in the same conditions.

In the third and fourth components graph (Fig. 3), the loadings plot (Fig. 2b) showed that the third latent vector captured the strong effect of rotational speed and inlet consistency. The fourth vector seemed related to freeness (CSF) effect. The fiber characteristics can be found in the center of the loading plot, showing they had no influence on these two latent vectors. The scores plot (Fig. 2a) clearly indicates that these latent vectors were not related to the pulp type, as the mapping of the three pulps was superimposed.

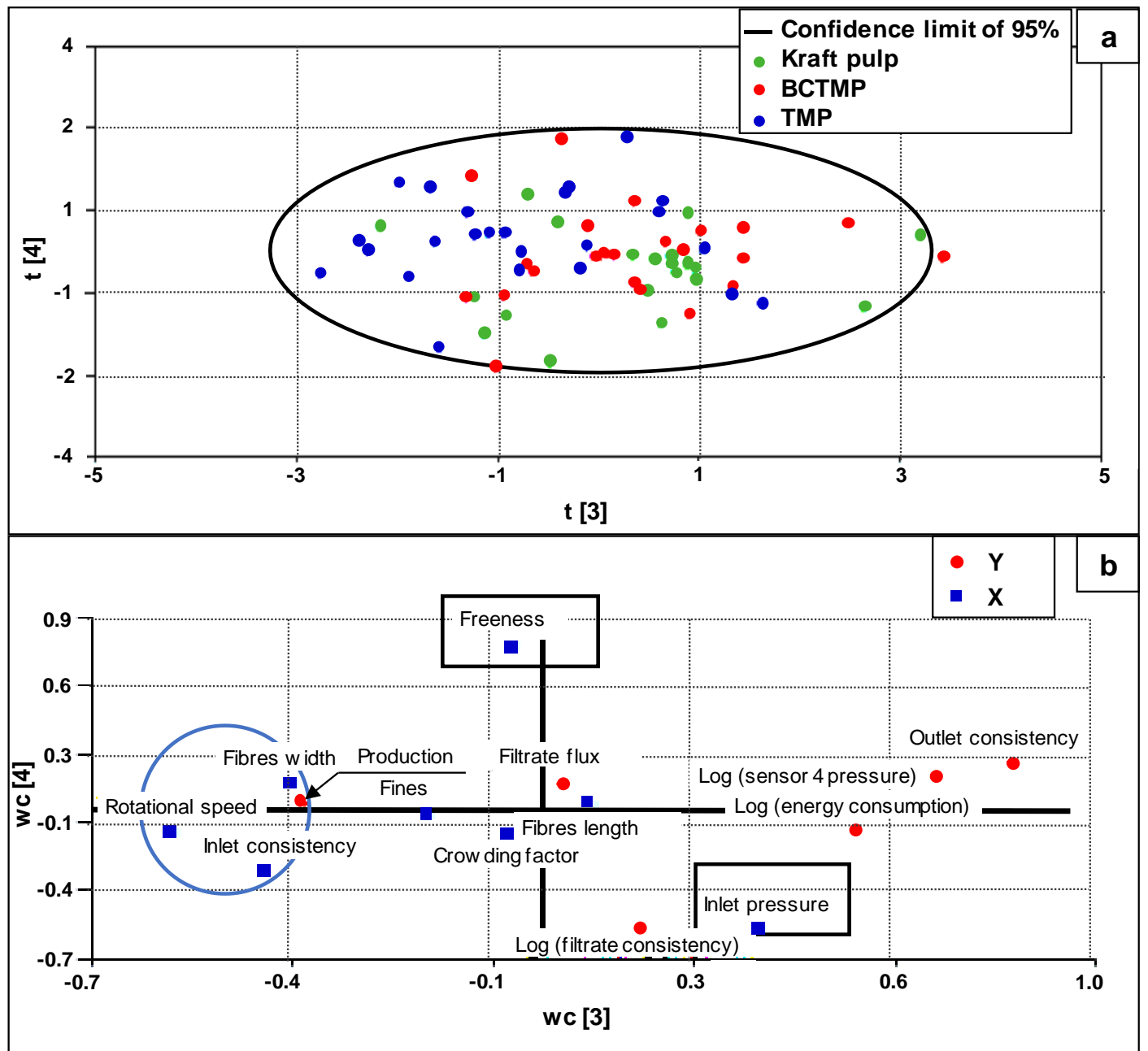

Fig. 3. Scores (a) and loadings (b) of the model for the third and fourth latent vectors

After analyzing the parameters, the model's goodness of fit $\mathrm{R}^{2}$ and goodness of prediction $\mathrm{Q}^{2}$ are summarized in Fig. 4. Compared to the JMP general statistical model, the multivariate general model performance was greatly increased. The $\mathrm{R}^{2}$ of the outlet consistency increased from 0.40 to $0.73,0.38$ to 0.73 for the filtrate consistency, 0.54 to 0.75 for the energy consumption, and 0.54 to 0.70 for the sensor 4 pressure. Thus, the model that included other pulp properties improved the prediction performance. In the end, 
the $\mathrm{Q}^{2}$ of the model was always higher than 0.60 . The Variables Importance on Projection (VIP) was also analyzed (Fig. 5).

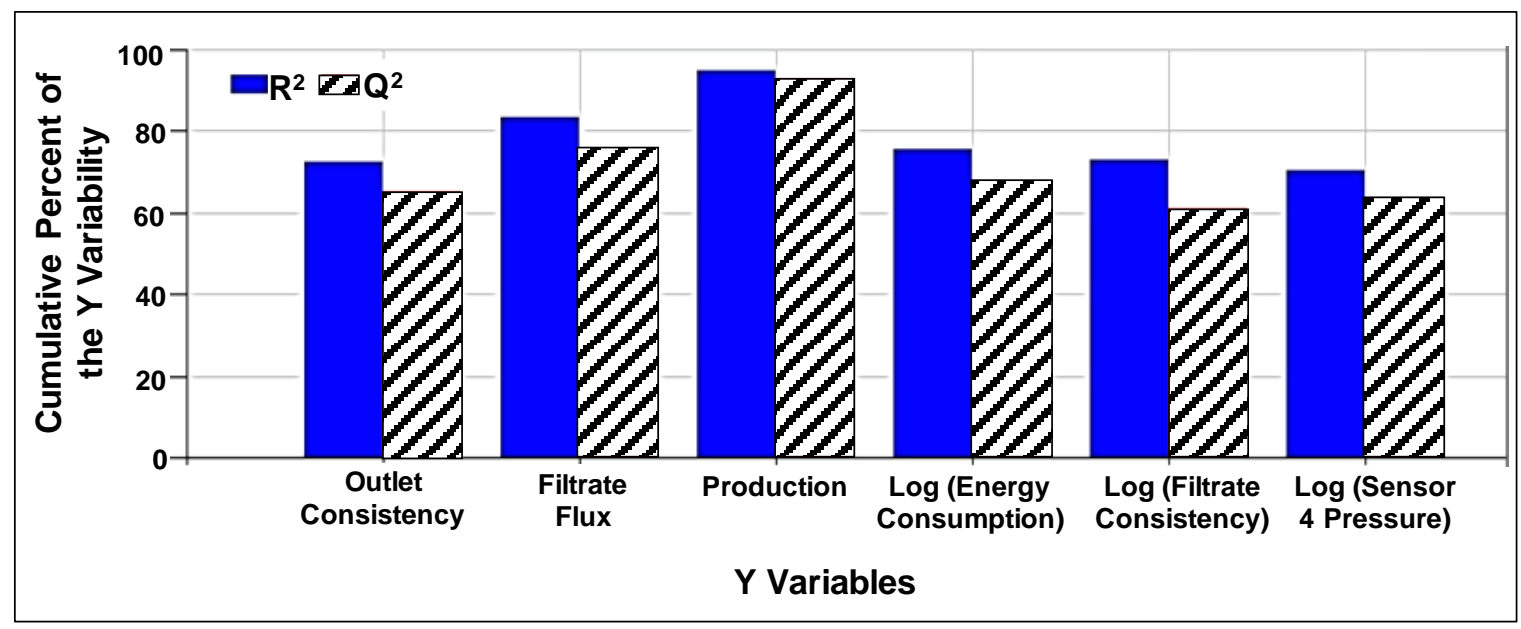

Fig. 4. Maximum percentages of each $Y$ variability explained by the PLS model

A variable is considered to have a significant effect when it has a VIP higher than 1. Hence, the outlet consistency (Fig. 5a) was more affected by the rotational speed, the feed consistency, and the fiber width. The filtrate flux (Fig. 5b) seemed affected by all the factors. The production (Fig. 5c) was affected the most by the crowding factor, the fines content, and the rotational speed, but not necessarily by the inlet pressure and consistency. The filtrate consistency (Fig. 5d) was mostly influenced by the feed consistency, the rotational speed, and the freeness. For the pressure at sensor 4 (Fig. 5e), the rotational speed and the feed consistency were the most evident influences. The energy consumption (Fig. 5f) was affected by the same parameters, the rotational speed and the feed consistency, but the fiber width and inlet pressure are to be considered. Globally, the rotational speed and the inlet consistency are the most important factors to consider for the screw press operation.

Table 8. Regression Coefficients of the Global Model in EXPLORE

\begin{tabular}{|c|c|c|c|c|c|c|}
\hline Terms & $\begin{array}{c}\text { Outlet } \\
\text { Consistency } \\
(\%)\end{array}$ & $\begin{array}{c}\text { Filtrate } \\
\text { Consistency } \\
(\%)\end{array}$ & $\begin{array}{c}\text { Filtrate } \\
\text { Flux } \\
(\mathrm{kg} / \mathrm{min})\end{array}$ & $\begin{array}{c}\text { Production } \\
\text { (odmt/d) }\end{array}$ & $\begin{array}{c}\text { Sensor 4 } \\
\text { Pressure } \\
(\mathrm{kPa})\end{array}$ & $\begin{array}{c}\text { Energy } \\
\text { Consumption } \\
(\mathrm{KWh} / \mathrm{kg})\end{array}$ \\
\hline Constant & 59.08 & 0.74 & 217.8 & -9.40 & 7.17 & 3.72 \\
\hline Rotational Speed & -0.53 & 0.02 & 3.58 & 0.16 & -0.05 & -0.004 \\
\hline Freeness & 0.013 & -0.002 & 0.38 & 0.02 & 0.001 & -0.001 \\
\hline Feed Consistency & 1.35 & -0.64 & -44.33 & 1.54 & 0.24 & -0.25 \\
\hline Feed Pressure & 0.02 & 0.04 & 4.32 & 0.08 & 0.005 & -0.005 \\
\hline Fibres Length & 4.48 & -1.08 & -16.58 & -2.33 & 0.35 & -0.12 \\
\hline Fibres Width & -0.63 & -0.04 & -3.83 & 0.07 & -0.05 & -0.06 \\
\hline Fines & -0.14 & 0.02 & -0.19 & 0.03 & -0.01 & -0.0004 \\
\hline Crowding Factor & -0.02 & 0.004 & 0.09 & 0.03 & -0.001 & -0.0008 \\
\hline$R^{2}$ & 0.73 & 0.73 & 0.83 & 0.94 & 0.70 & 0.75 \\
\hline
\end{tabular}



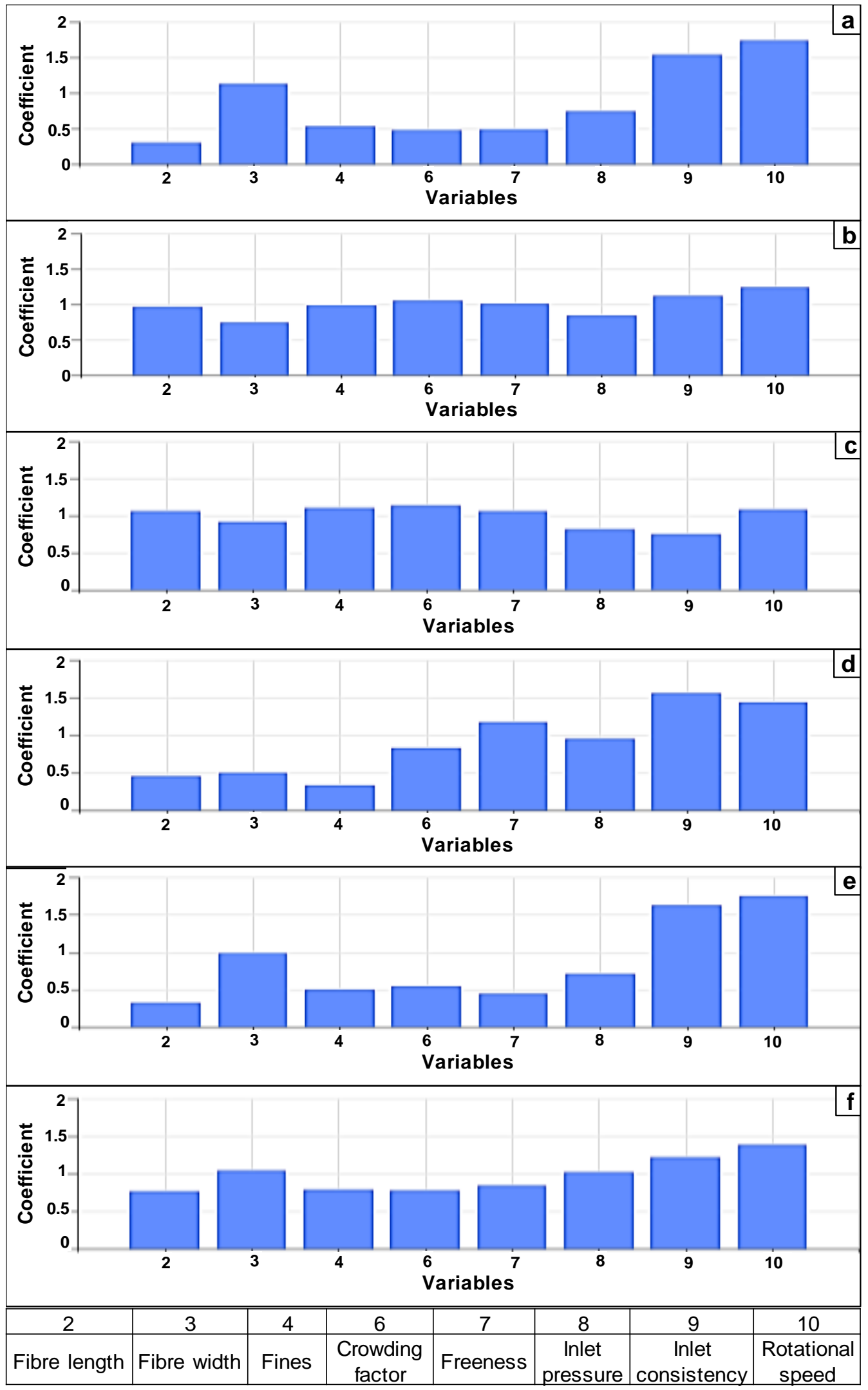

Fig. 5. VIP of the multivariate model, outlet consistency (a), filtrate flux (b), production (c), filtrate consistency (d), sensor 4 pressure (e), and energy consumption (f) 
Surprisingly, the fiber width also has a strong impact on all the response variables except for filtrate flux and consistency. The other pulp characteristics also have an important impact but for different variables. Therefore, the rotational speed, the freeness, the feed consistency combined with the fibers' properties and fines percentage should be considered when dewatering pulp in a screw press. The prediction equation coefficients are summarized in Table 8.

\section{CONCLUSIONS}

1. For each pulp individually, a statistical predictive model could calculate the press outputs very well. The model with interactions was used, and the $\mathrm{R}^{2}$ ranged between 0.65 and 0.97 , which is a very good regression value. It also showed that the fiber type is not the main cause of the difference between the pulps. The fiber length was the main factor to characterize each pulp individually in regards to the crowding factor.

2. The global model in JMP, with interactions, was only predicting the filtrate flux and the production very well. For the other outputs, the $\mathrm{R}^{2}$ was lower than 0.50 . This was judged not sufficient to have a good description of the screw press design. However, in agreement with previous findings (El Idrissi et al. 2019), the statistical modeling showed that the rotational speed, the freeness, and the feed consistency are the most important factors as they were found to influence most of the press outputs, either alone or combined with each other.

3. In addition to the five parameters studied in JMP, four more variables (fibers length, fibers width, fines content, and crowding factor) were added in a multivariate analysis

global model. The counter-pressure was rejected after noticing it has no significant effect on most of the outputs. By using the principal component multivariate analysis, the $\mathrm{R}^{2}$ of the model increased greatly and had a goodness of prediction $\mathrm{Q}^{2}$ higher than 0.60. Compared to the JMP general statistical model, the multivariate general model performance was noticeably increased. From an application point of view, the multivariate model is more general and flexible. Further experiments with other types of pulp will be undergone to validate, or further improve the model.

\section{ACKNOWLEDGMENTS}

The financial support from the Natural Sciences and Engineering Research Council of Canada (NSERC) and Valmet is gratefully acknowledged.

\section{REFERENCES CITED}

Bredeson, D. K. (1983). “Mechanical oil extraction,” J. Am. Oil. Chem. Soc. 60 (2), 211213. DOI: $10.1007 / \mathrm{BF} 02543484$

Eaves, T. S., Paterson, D. T., Hewitt, D. R., Balmforth, N. J., and Martinez, D. M. (2020). "Dewatering saturated, networked suspensions with a screw press," J. Eng. Math. 120, 1-28. DOI: 10.1007/s10665-019-10029-3

Egenes, T. H., and Helle, T. (1992). "Flow Characteristics and water removal from pulp 
suspensions in a screw press," Pulp Pap-Canada 18(3), J93-J99.

Egenes, T. H., and Helle, T. (1994). "Transport and drainage processes in a screw press. New light on a major part of the pulping process," Pulp Pap-Canada 95(2), 38-43.

El Idrissi, B., Loranger, É., Lanouette, R., Bousquet, J. P., and Martinez, M. (2019). "Dewatering parameters in a screw press and their influence on the screw press outputs," Chem. Eng. Res. Des. 152, 300-308. DOI: 10.1016/j.cherd.2019.10.001

Fangueiro, D., Senbayran, M., Trindade, H., and Chadwick, D. (2008). "Cattle slurry treatment by screw press separation and chemically enhanced settling: Effect on greenhouse gas emissions after land spreading and grass yield," Bioresource Technol. 99(15), 7132-7142. DOI: 10.1016/j.biortech.2007.12.069

Indartono, Y. S., Heriawan, H., and Kartika, I. A. (2019). "Innovative and flexible single screw press for the oil extraction of Calophyllum seeds," Res. Agr. Eng. 65(3), 91-97. DOI: $10.17221 / 85 / 2018-\mathrm{RAE}$

Kerekes, R., and Schell, C. (1992). "Regimes by a crowding factor," J. Pulp Pap. Sci. 18(1), J32-J38.

Martinez, D., Buckley, K., Jivan, S., Lindstrom, A., Thiruvengadaswamy, R., Olson, J., Ruth, T., and Kerekes, R. (2001). "Characterizing the mobility of papermaking fibres during sedimentation," in: $12^{\text {th }}$ Fundamental Res. Symp., Oxford, UK, pp. 225-254.

Martinez, D., Kiiskinen, H., Ahlman, A-K., and Kerekes, R. (2003). "On the mobility of flowing papermaking suspensions and its relationship to formation," J. Pulp Pap. Sci. 29(10), 341-347.

Mason, S. G. (1954). "Fibre motions and flocculation,” Tappi J. 37(11), 494-501.

Meyer, T., Amin, P., Allen, D. G., and Tran, H. (2018). "Dewatering of pulp and paper mill biosludge and primary sludge," J. Environ. Chem. Eng. 6(5), 6317-6321. DOI: 10.1016/j.jece.2018.09.037

Ringnér, J. (1995). The Influence of Fibre Length Distribution on the Network Strength of Fibre Suspensions, Master's Thesis, Chalmers University, Goteborg, Sweden.

Sall, J., Stephens, M. L., Lehman, A., and Loring, S. (2017). JMP Start Statistics: A Guide to Statistics and Data Analysis Using JMP, SAS, Cary, North Carolina.

Shirato, M., Hayashi, N., Iwata, M., Murase, T., and Ogawa, Y. (1985). "Continuous expression of slurry in a screw press," Int. Chem. Eng. 25(1), 88-96.

Soszyński, R. M. (1987). "The formation and properties of coherent flocs in fibre suspensions," Ph.D Dissertation, University of British Columbia, Vancouver, BC, Canada.

TAPPI T240 om-93. (1993). “Consistency (concentration) of pulp suspensions," TAPPI Press, Atlanta, GA.

TAPPI T227 om-99. (1999). "Freeness of pulp (Canadian standard method)," TAPPI Press, Atlanta, GA.

Xu, J. Q., and Duffy, G. (2001). "Operational parameters in screw press dewatering" Appita J. 54(4), 369-375.

Yan, Q., Miazek, K., Grande, P. M., Dominguez de Maria, P., Leitner, W., and Modigell, M. (2014). "Mechanical pretreatment in a screw press affecting chemical pulping of lignocellulosic biomass," Energ. Fuel 28(11), 6981-6987. DOI: 10.1021/ef501706w

Article submitted: March 18, 2020; Peer review completed: May 24, 2020; Revised version received and accepted: June 9, 2020; Published: June 15, 2020.

DOI: $10.15376 /$ biores.15.3.5899-5912 